\title{
Treatment of hypertension with a fixed-dose combination of bisoprolol and amlodipine in daily practice: Results of a multinational non-investigational study
}

\author{
Hostalek $\mathrm{U}^{*}$ and Koch EMW \\ ${ }^{1}$ Merck KGaA, Darmstadt Germany \\ ${ }^{2}$ Clinical Research, Alsbach, Germany
}

\begin{abstract}
Objective: Primary study objective was assessing patient adherence to the fixed dose combination (FDC) of bisoprolol and amlodipine in daily practice. Secondary study objectives included the assessment of blood pressure values and heart rate.

Material and methods: This non-investigational study was carried out in six countries in Eastern Europe, namely Czech Republic, Hungary, Poland, Romania, Serbia, and Slovakia. 12,424 patients > 18 years of age with essential hypertension were recruited if they had been switched from a free combination to the FDC at least 4 weeks prior to recruitment. Exclusion criteria included pregnancy, lactation, any contraindication to the FDC and other antihypertensive treatment. Adherence was measured by tablet count (tablets taken divided by tablets prescribed, times 100) and defined as follows: excellent >90\%, good 76-90\%, moderate $50-75 \%$, bad $<50 \%$. Other patient data, clinical findings such as systolic and diastolic blood pressure, pulse pressure and heart rate were recorded upon availability at study start and after 6 months of FDC treatment.

Results: Data of 12,242 patients (mean age: 59.1 years' gender: $49 \%$ female, $51 \%$ male) were documented. The average daily doses of the FDC were $5.8 \mathrm{mg}$ bisoprolol and $6.3 \mathrm{mg}$ amlodipine, differing only slightly from those of the free combination $(5.5 \mathrm{mg}$ and $6.1 \mathrm{mg}$, respectively). After 6 months of FDC-treatment, $99 \%$ of the participants of the study showed an excellent or a good adherence. This good or excellent adherence may have led to the observed reduction of the systolic and the diastolic blood pressure of $16.5 \mathrm{mmHg}$ for systolic and $9.5 \mathrm{mmHg}$ for diastolic blood pressure values. (Cohen's D Efficient-size 1.26 and 1.04). In addition, pulse pressure decreased by $7.1 \mathrm{mmHg}$ (Cohen's D Efficient-size 0.6 ). The heart rate decreased by a mean of $7.7 \mathrm{bpm}$ (Cohen's D Efficient-size 0.85 ). There was a certain influence of the baseline BMI values on the blood pressure values at study start, but not on the blood pressure values after 6 months of FDC treatment.

Conclusion: These study results demonstrate that the FDC leads to an excellent patient adherence and therefore may result. Patients enrolled in the study also demonstrated good blood pressure control under the FDC that is crucial in the risk reduction of cardiovascular events. The key limitation of this study is that the study design does not allow a direct comparison of patient adherence under the free and the fixed dose combination.
\end{abstract}

\section{Introduction and study objective}

Hypertension is recognized as a major risk factor for coronary, cerebral, and renal vascular diseases [1]. There are about 600 million hypertensive people in the world [2]. Hypertension is responsible for $57 \%$ of all stroke-related deaths and $24 \%$ of all coronary heart diseaserelated deaths [3]. There is a need for increased awareness, diagnosis, and management of hypertension.

The recent European Society of Cardiology/European Society of Hypertension guidelines for the management of hypertension state that 'monotherapy allows to achieve blood pressure (BP) target in only a limited number of hypertensive subjects' and that 'use of more than 1 agent is necessary to achieve target BP in most subjects' [4]. The $7^{\text {th }}$ Joint National Committee on Prevention, Detection, Evaluation, and Treatment of High Blood Pressure recommends that when the BP is more than $20 / 10 \mathrm{mmHg}$ above goal, consideration should be given to initiating therapy with 2 drugs, either as separate prescriptions or in FDC [5]. In the randomized trials of antihypertensive therapy conducted during the 1970s and 1980s, in which very large doses of single drug were employed as initial therapy, more than $50 \%$ of subjects required treatment with combination therapy to achieve the BP goal indicated in the trial protocol. This implies that an increase in the dose of the initial antihypertensive agent does not usually significantly increase the effectiveness of monotherapy. It is well known that high doses of almost all antihypertensive agents increase the risk and the severity of adverse effects. Adverse effects of drugs are the main cause for the low adherence of subjects with antihypertensive therapy in clinical practice. Essential hypertension has multiple mechanisms, and rational combination therapy allows interference with more than 1 of these mechanisms. Rational combination therapy not only reduces adverse effects because of the use of low doses of each combined agent, but can also take advantage of counteractions that each of the combined agents can exert on the undesirable actions of the other

Correspondence to: Ulrike Hostalek, Merck KGaA, Darmstadt, Germany, Tel: +49615172 3106; Fax: +496151 72 913106; E-mail: ulrike.gottwaldhostalek@merckgroup.com

Key words: adherence, hypertension, bisoprolol, amlodipine, fixed dose combination

Received: October 23, 2016; Accepted: November 21, 2016; Published: November 24, 2016 
agent [6]. Hence, it is logical, and has been practically demonstrated that low dose combination agents, because of additive effect on BP, would expose subjects to fewer side-effects, with equal or better BP control. Thus, combination therapy has an important place in the routine management of hypertension.

However, it must be considered that for many, especially elderly, patients, the rules for taking multiple medications can be very distressing and lead to misconduct and to inadequate adherence. Because of the above-mentioned facts, a fixed combination tablet of the beta-blocker bisoprolol and the calcium channel blocker amlodipine in the strengths of $5 \mathrm{mg} / 5 \mathrm{mg}, 5 \mathrm{mg} / 10 \mathrm{mg}, 10 \mathrm{mg} / 5 \mathrm{mg}$ and $10 \mathrm{mg} / 10 \mathrm{mg}$ was developed as substitution for the free combination. Bisoprolol is a highly beta1-adrenoceptor-selective antagonist devoid of any intrinsic sympathomimetic activity (ISA). Pharmacological features of bisoprolol are essentially related to its high betal-selectivity and confer substantial clinical advantages to the drug compared with non-selective agents in terms of their respiratory, hemodynamic, and metabolic effects [7-9]. Amlodipine is a long-acting calcium channel blocker of the dihydropyridine class. Amlodipine inhibits calcium ion influx across cell membranes selectively, with a greater effect on vascular smooth muscle cells than on cardiac muscle cells [10-12]. Both bisoprolol and amlodipine are widely used antihypertensive drugs. The combination of amlodipine and bisoprolol demonstrates an additive effect since both the drugs have different and complementary modes of actions to reduce BP: for example, a vascular selective calcium antagonist like amlodipine lowers total peripheral resistance and a $\beta-1$ selective blocker like bisoprolol lowers heart rate (HR) and, thus, cardiac output [13-15]. There have been several studies that have evaluated the effects of bisoprolol and amlodipine separately, as monotherapy, in the management of essential hypertension [16]. There also have been some studies that have evaluated the FDC of Bisoprolol and Amlodipine, not only to evaluate bioequivalence, but also the efficacy and safety on the treatment of hypertension [17-21]. The first study on the FDC of Bisoprolol and Amlodipine was carried out by Mehta et al. [17]. The study investigated the efficacy and safety of the FDC in 106 subjects suffering from mild to moderate essential hypertension. The study showed that a once daily administration of the FDC of Amlodipine/ Bisoprolol $5 \mathrm{mg} / 2.5 \mathrm{mg}$ significantly lowered both SBP and DBP, and was well tolerated and safe at the end of 8 weeks of treatment. Response rate was $98 \%$.

Further experiences with a FDC of Bisoprolol and Amlodipine were gained from an observational study of 801 subjects with stage II essential hypertension [18]. Patients received a FDC of $5 \mathrm{mg}$ Bisoprolol and $5 \mathrm{mg}$ Amlodipine once daily for 4 weeks. Responders were supposed to have a SBP $<140 \mathrm{mmHg}$ and a DBP $<90 \mathrm{mmHg}$ at the end of treatment. The responder rate after 4 weeks of treatment was $82.5 \%$. Excellent to good efficacy and tolerability were scored in $91.4 \%$ and $90.3 \%$ of the patients. The most frequently reported AE was edema in $8 \%$ of the patients. Other adverse events were headache (4\%), fatigue (3\%), leg cramps (3\%), and dry mouth (1\%). All AEs were mild. The authors concluded that the daily application of a FDC of Bisoprolol $5 \mathrm{mg}$ and Amlodipine $5 \mathrm{mg}$ in stage II essential hypertension was effective, safe, and well tolerated. Shirure et al. [19] demonstrated the superiority of the FDC of Bisoprolol $5 \mathrm{mg}$ and Amlodipine $5 \mathrm{mg}$ in 60 hypertensive patients, aged 40-65 years. In those patients not responding to either Amlodipine $5 \mathrm{mg}$ or Bisoprolol $5 \mathrm{mg}$ alone, after addition of the second agent, mean SBP and DBP values decreased significantly after 2 weeks. Hostalek et al. [20] carried out an observational study with Concor AM in several thousand patients in Poland. The study results clearly demonstrate the strong adherence under the FDC of Bisoprolol and Amlodipine. Consequently, BP control was improved and, thus, the risk of cardiovascular events decreased. The primary objective of the phase III trial by Hostalek et al. [21] was to investigate the efficacy of the FDC of bisoprolol and amlodipine in 200 hypertensive patients, whose BP could not be controlled by either monotherapy (Bisoprolol $5 \mathrm{mg}$ or Amlodipine $5 \mathrm{mg}$ ) alone. Based on the primary efficacy endpoint of the trial, subjects on pre-study Amlodipine monotherapy and subjects on pre-study Bisoprolol monotherapy reported mean SBP reductions of $24.7 \mathrm{mmHg}$ (95\% CI: -27.1; -22.3) and $25.9 \mathrm{mmHg}(95 \%$ CI: -28.6; -23.3), respectively, from baseline to Week 18 (all p-values were $<0.001)$. Also, DBP, as well as HR, decreased significantly under the FDC compared to the values under either monotherapy $(\mathrm{p}<0.001)$ Thus, it could be shown that adding the second component of the FDC led to a statistically significant and clinically relevant decrease in SBP. In more than $80 \%$ of the patients, BP could already be controlled under the lowest strength of the FDC ( $5 \mathrm{mg} / 5 \mathrm{mg}$ after 6 weeks of treatment). The most important advantage of a FDC compared to the free combination is the expected better patient adherence. Thus, the present study was conducted as a non-investigational study to evaluate the adherence of the FDC in daily practice in patients who had been switched from the free to the fixed dose combination prior to recruitment.

\section{Methods}

Hypertensive patients aged over 18 years from Czech Republic, Hungary, Poland, Romania, Serbia, and Slovakia, who had been switched from a free combination of bisoprolol and amlodipine to the fixed dose combination (FDC) at least four weeks prior to recruitment were included in this non-interventional study. Prior to inclusion in the study, patients were informed of the nature, significance and scope of the study and gave their consent to participate and to have their data used in an anonymized way. At the screening examination, past medical history data and clinical findings were recorded and blood pressure values and laboratory values determined upon availability. Follow-up examinations occurred after 6 months. At this point, the number of prescribed tablets taken by the patients was checked to assess adherence ( $>90 \%=$ =xcellent, $\quad 76-90 \%=$ good, $\quad 50-75 \%=$ moderate, $<50 \%=$ poor). Blood pressure and heart rate values were also documented upon availability. Blood pressure was measured in a supine position after at least 5 minutes' rest. Additionally, patients were asked to assess the new treatment concept subjectively.

\section{Analysis}

All entries in the CRFs were transferred for evaluation in the BIAS file (Biometric analysis of samples, Hanns Ackerman, Univ. Frankfurt). As methods were used calculation of mean, standard deviation, median, quartiles, and the Cohen's D for Effect-size (M1-M2/s-pooled).

\section{Results}

12,424 hypertensive patients were recruited for the study in six CEE countries. In 995 patients, the documentation did not allow the evaluation of the primary target parameter adherence. All patients had been previously prescribed bisoprolol and amlodipine in free combination and had been switched to the FDC prior to recruitment. Demographic data are summarized in Table 1 and 2. There were $49 \%$ female and $51 \%$ male patients. The mean age was 59.1 years with a broad range. The youngest patient was 19 years and the oldest 99 years old. There was no influence of the gender nor of the age on the blood pressure values at study start. There were 4,828 patients with concomitant cardiovascular disease (39\%) and 2,644 patients with type 
Hostalek U (2016) Treatment of hypertension with a fixed-dose combination of bisoprolol and amlodipine in daily practice: Results of a multinational noninvestigational study

2 diabetes (21\%). $13 \%$ of the patients had concomitant CV diseases and type 2 diabetes. 6,542 (54\%) of the patients were overweight (BMI>25) and another 3,289 (27\%) obese (BMI $>30)$. Almost half of the patients stated to be non-smokers (50\%). $25 \%$ each was still smoking or had quitted smoking. $38 \%$ of the patients were not drinking any alcohol, the rest was consuming slightly $(50 \%)$, moderately $(11 \%)$, or regularly (1\%).

All patients had been pretreated once daily with a free combination of bisoprolol (mean $5.5 \pm 1.5 \mathrm{mg}$ ) and amlodipine (mean $6.1 \pm 2 \mathrm{mg}$ ). Most patients $(8,497,72 \%)$ were treated with the lowest possible combination of $5 \mathrm{mg}$ bisoprolol and $5 \mathrm{mg}$ amlodipine. The average duration of free combination treatment prior to switch to FDC was 16.8 months $(\mathrm{SD} \pm 15)$. The mean duration of the hypertension was $8.8 \pm 6$ years.

Mean, median, and quartile 1 and 3 values for systolic and diastolic blood pressure at study start demonstrate that a big part of patients did not reach the target value for systolic blood pressure of $<140 \mathrm{mmHg}$,

Table 1. Demographic data I.

\begin{tabular}{|l|c|c|}
\hline & $\mathbf{N}$ & $\mathbf{\%}$ \\
\hline Participants & 12,424 & \\
\hline Gender, n=12,368 & & 51 \\
Male & 6,314 & 49 \\
\hline Female & 6,054 & 39 \\
\hline Cardiovascular co-morbidities $\mathrm{n}=12,216$ & 4,828 & 21 \\
\hline Diabetes type 2 $\mathrm{n}=12,216$ & 2,644 & 13 \\
\hline CV co-morbidity plus diabetes, $\mathrm{n}=12,216$ & 1,598 & 2 \\
\hline Liver disease n=12,089 & 210 & 3 \\
\hline Kidney damage n=12,256 & 410 & 25 \\
\hline Smoking habits, $\mathrm{n}=12,152$ & & 25 \\
\hline Smoker & 3,013 & 50 \\
\hline Ex-smoker & 3,033 & 38 \\
\hline No smoking & 6,106 & 50 \\
\hline Alcohol consumption, $\mathbf{n}=\mathbf{1 2 , 1 4 8}$ & & 11 \\
No alcohol & 4,566 & 1 \\
\hline Little alcohol (1x weekly) & 6,075 & 98 \\
moderate alcohol (2-4x weekly) & 1,354 & 2 \\
regular (5-7x weekly) & 137 & 0 \\
\hline Diet, n=12,122 & & \\
normal & 11,906 & 194 \\
\hline vegetarian & 20 & \\
vegan & & \\
\hline
\end{tabular}

Table 2. Demographic data II.

\begin{tabular}{|l|c|c|c|}
\hline Parameters & Mean (SD) & median & Q1-Q3 \\
\hline Age (years) $\mathrm{n}=12,343$ & $59.1(11)$ & 60 & $52-67$ \\
\hline Height (cm) $\mathrm{n}=12,343$ & $169.9(9)$ & 170 & $164-177$ \\
\hline Weight (kg) $\mathrm{n}=12,335$ & $81.5(13)$ & 80 & $72-90$ \\
\hline BMI (kg/m $\left.\mathbf{m}^{2}\right) \mathrm{n}=12,190$ & $28.2(4)$ & 28.5 & $25.6-31.3$ \\
\hline Systolic blood pressure (mmHg) $\mathrm{n}=12,383$ & $147.6(16)$ & 148 & $138-160$ \\
\hline Diastolic blood pressure (mmHg) $\mathrm{n}=12,373$ & $88.3(10)$ & 90 & $80-95$ \\
\hline Pulse beat/min $\mathrm{n}=12,333$ & $75.8(10)$ & 76 & $68-82$ \\
\hline Pulse Pressure $\mathrm{n}=12,369$ & $59.3(13)$ & 60 & $50-70$ \\
\hline Duration of hypertension (years) $\mathrm{n}=12,103$ & $8.8(6)$ & 6 & $3-12$ \\
\hline $\begin{array}{l}\text { Duration of free combination prior to switch } \\
\text { (months) } \mathrm{n}=11,974\end{array}$ & $16.8(15)$ & 12 & $6-24$ \\
\hline $\begin{array}{l}\text { Dosages (free combination) } \\
\text { Bisoprolol (mg daily) } \mathrm{n}=12,244 \\
\text { Amlodipine (mg daily) } \mathrm{n}=12,251\end{array}$ & $5.5(2)$ & 5 & $5-5$ \\
\hline $\begin{array}{l}\text { Dosages FDC } \\
\text { Bisoprolol (mg daily) } \mathrm{n}=12,244 \\
\text { Amlodipine (mg daily) } \mathrm{n}=12,251\end{array}$ & $6.1(2)$ & 5 & $5-5$ \\
\hline $\begin{array}{l}\text { Time of FDC prior to recruitment (weeks) } \\
\text { n=12,041 }\end{array}$ & $4.9(1.5)$ & 5 & $5-5$ \\
\hline
\end{tabular}

namely 4,179 (34\%). Mean duration of hypertension prior to study recruitment was 8.8 years $(\mathrm{SD} \pm 6)$.

The average dose in the fixed combination (bisoprolol: $5.8 \mathrm{mg}$ \pm 2 , amlodipine: $6.3 \mathrm{mg} \pm 3$ ) was not considerably different from the previous dose of both products in the free combinations. Table 3 compares the dosage strengths of bisoprolol and amlodipine in free and fixed dose combination. When switching from the free to the fixed dose combinations no changes in single doses of bisoprolol and amlodipine were performed in about $80 \%$ of the cases. Adherence data after 6 months of treatment are only available for 11,429 (92\%) of the patients. The data is summarized in Table 4. It was expected that more than $90 \%$ of the patients at Visit 5 show an excellent or good adherence. The adherence of $99 \%$ of the patients was good to excellent. Systolic blood pressure decreased by $16.5 \mathrm{mmHg}$ (Effect size: $\mathrm{d}=1.26$ ), and the diastolic blood pressure by $9.5 \mathrm{mmHg}($ Effect size $\mathrm{d}=1.04)$. Similarly, the pulse pressure and heart rate values fell over the 6 months of treatment (Table 5). The changes in blood pressure values are described in Table 6.

Table 3. Comparison of dosing between free and fixed-dose combination.

\begin{tabular}{|l|c|c|}
\hline & $\begin{array}{c}\text { Free combination } \\
\mathbf{n = 1 1 , 8 6 9} \\
\mathbf{n}(\mathbf{\%})\end{array}$ & $\begin{array}{c}\text { FDC } \\
\mathbf{n = 1 1 , 8 1 8} \\
\mathbf{n}(\mathbf{\%})\end{array}$ \\
\hline Bisoprolol 5 mg/Amlodipine 5 $\mathbf{~ m g}$ & $8,498(72)$ & $7,690(65)$ \\
\hline Bisoprolol 10 $\mathbf{~ m g / A m l o d i p i n e ~ 5 ~} \mathbf{~ m g}$ & $729(6)$ & $933(8)$ \\
\hline Bisoprolol 5 $\mathbf{~ m g / A m l o d i p i n e ~ 1 0 ~} \mathbf{~ m g}$ & $2,031(17)$ & $2,222(19)$ \\
\hline Bisoprolol 10 mg/Amlodipine 10 $\mathbf{~ m g}$ & $611(5)$ & $973(8)$ \\
\hline & & \\
\hline Daily Doses & Mean (SD) & Mean (SD) \\
\hline Bisoprolol mg/d & Median; Q1-Q3 & Median; Q1-Q3 \\
\hline Amlodipine mg/d & $5.5(1.5)$ & $5.8(2)$ \\
& $5 ; 5-5$ & $5 ; 5-5$ \\
\hline
\end{tabular}

Table 4. Patient adherence at Visit 5 (after 6 months).

\begin{tabular}{|l|c|c|}
\hline $\begin{array}{l}\text { Adherence } \\
\text { N=11,429 }\end{array}$ & $\mathbf{N}$ & $\mathbf{\%}$ \\
\hline Excellent (>90\% of prescribed tablets taken) & 9,610 & 84 \\
\hline Good (76-90\% of prescribed tablets taken) & 1,689 & 15 \\
\hline Moderate (51-75\% of prescribed tablets taken) & 107 & 1 \\
\hline Bad (<50\% of prescribed tablets taken) & 23 & \\
\hline Total & 11,429 & 100.0 \\
\hline Good to excellent $(\mathbf{Z 7 6} \%)$ adherence & $\mathbf{1 1 , 2 9 9}$ & $\mathbf{9 9}$ \\
\hline
\end{tabular}

Table 5. Changes in blood pressure, pulse pressure and heart rate.

\begin{tabular}{|c|c|c|c|c|}
\hline & $\begin{array}{c}\text { SBP } \\
(\mathbf{m m H g})\end{array}$ & $\begin{array}{c}\text { DBP } \\
(\mathbf{m m H g})\end{array}$ & $\begin{array}{l}\text { Pulse pressure } \\
\text { (mmHg) }\end{array}$ & $\begin{array}{l}\text { Heart rate } \\
\text { (bpm) }\end{array}$ \\
\hline & $\begin{array}{c}\mathbf{N} \\
\text { Mean (SD) } \\
\text { median } \\
\text { Q1 - Q3 }\end{array}$ & $\begin{array}{c}\mathrm{N} \\
\text { Mean (SD) } \\
\text { median } \\
\text { Q1 - Q3 }\end{array}$ & $\begin{array}{c}\mathbf{N} \\
\text { Mean (SD) } \\
\text { median } \\
\text { Q1 - Q3 }\end{array}$ & $\begin{array}{c}\mathrm{N} \\
\text { Mean (SD) } \\
\text { median } \\
\text { Q1 - Q3 }\end{array}$ \\
\hline Visit I (Study start) & $\begin{array}{c}\mathbf{1 2 , 3 8 3} \\
147.6(16) \\
148 \\
138-160\end{array}$ & $\begin{array}{c}\mathbf{1 2 , 3 7 3} \\
88.3(10) \\
90 \\
80-95\end{array}$ & $\begin{array}{c}\mathbf{1 2 , 3 6 9} \\
59.3(13) \\
60 \\
50-70\end{array}$ & $\begin{array}{c}\mathbf{1 2 , 3 3 3} \\
75.8(10) \\
76 \\
68-82\end{array}$ \\
\hline Visit IV (after 6 months) & $\begin{array}{c}\mathbf{1 1}, \mathbf{4 7 2} \\
131.2(10) \\
130 \\
125-139\end{array}$ & $\begin{array}{c}\mathbf{1 1 , 4 6 3} \\
78.9(7) \\
80 \\
75-83\end{array}$ & $\begin{array}{c}\mathbf{1 1 , 4 5 7} \\
52.3(10) \\
50 \\
45-60\end{array}$ & $\begin{array}{c}\mathbf{1 1 , 4 0 8} \\
68.4(7) \\
68 \\
64-72\end{array}$ \\
\hline Difference mean+/-SD & $\begin{array}{c}\mathbf{1 1 , 4 3 3} \\
16.5(15) \\
15 \\
5-27\end{array}$ & $\begin{array}{c}\mathbf{1 1 , 4 1 7} \\
9.5(11) \\
10 \\
0-16\end{array}$ & $\begin{array}{c}\mathbf{1 1 , 4 0 7} \\
7.1(14) \\
5 \\
0-15\end{array}$ & $\begin{array}{c}\mathbf{1 1 , 3 2 2} \\
7.7(10) \\
7 \\
0-14\end{array}$ \\
\hline Cohen's effect size & 1.26 & 1.04 & 0.6 & 0.85 \\
\hline
\end{tabular}


Hostalek U (2016) Treatment of hypertension with a fixed-dose combination of bisoprolol and amlodipine in daily practice: Results of a multinational noninvestigational study

Table 6. Changes in blood and pulse pressure values.

\begin{tabular}{|l|c|c|c|}
\hline & Increase $>\mathbf{1 0} \mathbf{~ m m H g}$ & Increase 0-10 $\mathbf{~ m m H g}$ & Decrease 1-10 $\mathbf{~ m m H g}$ \\
\hline SBP & $\mathbf{N ~ ( \% )}$ & $\mathbf{N}(\mathbf{\%})$ & $\mathbf{N}(\mathbf{\%})$ \\
\hline DBP & $554(5)$ & $1,478(13)$ & $3,031(27)$ \\
\hline Pulse Pressure & $630(5)$ & $2,468(22)$ & $4,064(36)$ \\
\hline
\end{tabular}

Table 7. Blood pressure, pulse pressure and heart at study start and after 6 months' FDC treatment per BMI group.

\begin{tabular}{|c|c|c|c|c|}
\hline & $\begin{array}{c}\text { Group } 1 \\
\text { BMI -19 kg/m } \text { m }^{2}\end{array}$ & $\begin{array}{c}\text { Group 2 } \\
\text { BMI }>19-25 \mathrm{~kg} / \mathrm{m}^{2}\end{array}$ & $\begin{array}{c}\text { Group } 3 \\
\text { BMI }>25-30 \mathrm{~kg} / \mathrm{m}^{2}\end{array}$ & $\begin{array}{c}\text { Group } 4 \\
\text { BMI }>30 \mathrm{~kg} / \mathrm{m}^{2}\end{array}$ \\
\hline Study Start & $\begin{array}{c}\mathrm{n} \\
\text { mean } \pm \mathrm{SD} \\
\text { median; } \mathrm{Q} 1-\mathrm{Q} 3\end{array}$ & $\begin{array}{c}\mathrm{n} \\
\text { mean } \pm \mathrm{SD} \\
\text { median; } \mathrm{Q} 1-\mathrm{Q} 3\end{array}$ & $\begin{array}{c}\mathrm{n} \\
\text { mean } \pm \mathrm{SD} \\
\text { median; } \mathrm{Q} 1-\mathrm{Q} 3\end{array}$ & $\begin{array}{c}\mathrm{n} \\
\text { mean } \pm \mathrm{SD} \\
\text { median; } \mathrm{Q} 1-\mathrm{Q} 3\end{array}$ \\
\hline Systolic blood pressure (mmHg) & $\begin{array}{c}32 \\
144.3 \pm 19 \\
141 ; 130-157\end{array}$ & $\begin{array}{c}2322 \\
144.8 \pm 16 \\
143.5 ; 132-155\end{array}$ & $\begin{array}{c}6527 \\
147.2 \pm 15 \\
146 ; 138-160\end{array}$ & $\begin{array}{c}3277 \\
150.3 \pm 16 \\
150 ; 140-160\end{array}$ \\
\hline Diastolic blood pressure (mmHg) & $\begin{array}{c}32 \\
86.1 \pm 12 \\
89 ; 72.5-99\end{array}$ & $\begin{array}{c}2319 \\
86,7 \pm 10 \\
87 ; 80-95\end{array}$ & $\begin{array}{c}6527 \\
88.2 \pm 10 \\
90 ; 80-95\end{array}$ & $\begin{array}{c}3272 \\
89.8 \pm 11 \\
90 ; 80-100\end{array}$ \\
\hline $\begin{array}{l}\text { Pulse pressure } \\
(\mathrm{mmHg})\end{array}$ & $\begin{array}{c}32 \\
58.3 \pm 13 \\
60 ; 50-65\end{array}$ & $\begin{array}{c}2319 \\
58.1 \pm 13 \\
56 ; 50-65\end{array}$ & $\begin{array}{c}6528 \\
59.1 \pm 12 \\
60 ; 50-65\end{array}$ & $\begin{array}{c}3271 \\
60.5 \pm 13 \\
60 ; 50-70\end{array}$ \\
\hline $\begin{array}{l}\text { Heart rate } \\
(\mathrm{bpm})\end{array}$ & $\begin{array}{c}32 \\
73.2 \pm 11 \\
72 ; 63-81\end{array}$ & $\begin{array}{c}2315 \\
75.1 \pm 11 \\
75 ; 68-80\end{array}$ & $\begin{array}{c}6528 \\
75.8 \pm 10 \\
76 ; 68-82\end{array}$ & $\begin{array}{c}3267 \\
76.3 \pm 10 \\
76 ; 69-84\end{array}$ \\
\hline \multicolumn{5}{|l|}{ After 6 months } \\
\hline Systolic blood pressure (mmHg) & $\begin{array}{c}29 \\
128.3 \pm 12 \\
130 ; 120-130\end{array}$ & $\begin{array}{c}2097 \\
130.3 \pm 10 \\
130 ; 120-138\end{array}$ & $\begin{array}{c}6030 \\
131.1 \pm 10 \\
130 ; 125-138\end{array}$ & $\begin{array}{c}3090 \\
131.8 \pm 10 \\
130 ; 125-140\end{array}$ \\
\hline Diastolic blood pressure (mmHg) & $\begin{array}{c}29 \\
76.6 \pm 7 \\
77 ; 70-80\end{array}$ & $\begin{array}{c}2093 \\
78.5 \pm 7 \\
80 ; 75-82\end{array}$ & $\begin{array}{c}6030 \\
78.9 \pm 7 \\
80 ; 75-82\end{array}$ & $\begin{array}{c}3088 \\
79.3 \pm 7 \\
80 ; 75-85\end{array}$ \\
\hline $\begin{array}{l}\text { Pulse pressure } \\
(\mathrm{mmHg})\end{array}$ & $\begin{array}{c}29 \\
51.6 \pm 9 \\
50 ; 45-60\end{array}$ & $\begin{array}{c}2092 \\
51.8 \pm 10 \\
50 ; 45-60\end{array}$ & $\begin{array}{c}6027 \\
52.2 \pm 10 \\
50 ; 45-60\end{array}$ & $\begin{array}{c}3086 \\
52.5 \pm 10 \\
50 ; 45-60\end{array}$ \\
\hline $\begin{array}{l}\text { Heart rate } \\
(\mathrm{bpm})\end{array}$ & $\begin{array}{c}29 \\
66.7 \pm 7 \\
65 ; 61.5-72\end{array}$ & $\begin{array}{c}2091 \\
68.3 \pm 7 \\
68 ; 64-72\end{array}$ & $\begin{array}{c}5995 \\
68.4 \pm 7 \\
68 ; 64-72\end{array}$ & $\begin{array}{c}3086 \\
68.3 \pm 7 \\
68 ; 64-72\end{array}$ \\
\hline
\end{tabular}

At study start, 3,664 patients (30\%) were not blood pressure controlled. After six months of treatment, this was only the case in 130 patients (1\%). The positive effect of the FDC treatment on blood pressure, pulse pressure and heart rate was true for all BMI groups (Table 7). Data on preference is available for 7,982 patients. Thereof, $7,184(90 \%)$ declared they would prefer treatment by the fixed combination.

\section{Adverse events}

Totally, 101 adverse events were reported. Most the adverse events were peripheral swelling [24] and joint swelling [11], followed by bradycardia, dizziness, and headache (5 each). Only 8 adverse events were considered serious, three cases of atrial fibrillation (one not related), two cases of cardiac failure, one case of cerebrovascular insufficiency, one case of angioedema and one head injury leading to death (not related) (Table 7). Totally, only 9 patients out of 12,424 patients $(0.07 \%)$ discontinued the study due to adverse events.

Overall, the FDC of bisoprolol and amlodipine was well tolerated.

\section{Discussion}

In long-term treatment of chronic diseases, such as hypertension, patient adherence is a severe problem. Patients often fail to control their blood pressure because they do not comply with pharmacologic therapy [19]. This is particularly true in patients with a high pill burden, e.g. in patients that need a combination of drugs for the treatment of hypertension and further disorders. On the other hand, strict blood pressure control is crucial to decrease the risk for cardiovascular events, particularly in hypertensive patients with additional risk factors such as type 2 diabetes. The general goal of antihypertensive therapy is to minimize the risks associated with blood pressure elevation without adversely affecting quality of life.

The importance of achieving goal BP in individual patients cannot be overemphasized. In major clinical trials, small differences in ontreatment BP frequently translate into major differences in clinical event rates. Recent data also suggest that inadequate BP control is itself an independent risk factor for the development of diabetes in hypertensive patients [20]. The biggest advantage of the FDC of bisoprolol and amlodipine is the reduction of tablets to be taken. It could be, therefore, assumed that the FDC will improve patient adherence $[17,18]$. In a meta-analysis of nine studies comparing administration of FDCs or their separate components, the adherence rate was improved by $26 \%$ in patients receiving FDCs [21].

First analyses of Polish patient populations from this study [17,19] demonstrated already the excellent patient adherence under the FDC of bisoprolol and amlodipine and the beneficial impact of a strong patient adherence on blood pressure, pulse pressure and heart rate control. This reinforces previous data with improved adherence under FDC [22]. With a sample size of more than 12,000 patients from sic European countries, the present multicenter study can be considered as representative, covering a wide range of ages. $22 \%$ of patients were aged 
Hostalek U (2016) Treatment of hypertension with a fixed-dose combination of bisoprolol and amlodipine in daily practice: Results of a multinational noninvestigational study

below 50 years and $16 \%$ were older than 70 years, so that, as expected, most patients suffering from high blood pressure were between 50 and 70 years of age.

In this patient population, $30 \%$ of the patients was not blood pressure controlled at study start. There was a clinically relevant reduction of systolic and diastolic blood pressure values during the study. This may be at least partly due to the good to very good adherence in $99 \%$ of the patients under the FDC. Same is true for the pulse pressure and heart rate. The high acceptance of the FDC by the patient was also shown by the fact that $90 \%$ of the patients preferred the FDC to the free combination at study end.

\section{Conclusion}

The FDC of bisoprolol and amlodipine leads to an excellent patient adherence. Patients enrolled in the study also demonstrated good blood pressure control under the FDC that is crucial in the risk reduction of cardiovascular events.

\section{Transparency}

This study was carried out as a company-sponsored trial by Merck KGaA. U. Hostalek is an employee of Merck KGaA, while EMW Koch is a consultant to the company.

U. Hostalek contributed to the conception and design of the study. EMW Koch and U. Hostalek were involved in the data analysis and interpretation. EMW Koch drafted this article. No assistance in the preparation of this article is to be declared.

\section{References}

1. Gaziano TA, Opie LH, Weinstein MC (2006) Cardiovascular disease prevention with a multidrug regimen in the developing world: a cost-effectiveness analysis. Lancet 368 : 679-686. [Crossref]

2. Vikrant S, Tiwari SC. (2001) Hypertension Pathogenesis, and Pathophysiology. Indian Acad Clin Med 2:141-61

3. Murray CJ, Lopez AD (1997) Alternative projections of mortality and disability by cause 1990-2020: Global Burden of Disease Study. Lancet 349: 1498-1504. [Crossref]

4. Joint Task Force of European and other Societies on Cardiovascular Disease Prevention in Clinical Practice. European Guidelines on cardiovascular disease prevention in clinical practice. Eur Heart J 2007; 28:1462-1536

5. Chobanian AV, Bakris GL, Black HR, Cushman WC, Green LA, et al. (2003) The seventh report of the Joint National Committee on Prevention, Detection, Evaluation, and Treatment of High Blood Pressure. JAMA 289:2560-70. [Crossref]

6. Zanchetti A. (1999) Contribution of fixed low-dose combinations to initial therapy in hypertension. Eur Heart $J$ suppl 1: L5-9

7. Bethge H, Litterer G, Wagner G, Prager G (1989) [The 24-hour-effect of bisoprolol on blood pressure at rest and during stress]. Fortschr Med 107: 153-158. [Crossref]
8. Smith C, Teitler M (1999) Beta-blocker selectivity at cloned human beta 1- and beta 2-adrenergic receptors. Cardiovasc Drugs Ther 13: 123-126. [Crossref]

9. Nuttall SL, Routledge HC, Kendall MJ (2003) A comparison of the beta1-selectivity of three beta1-selective beta-blockers. J Clin Pharm Ther 28: 179-186. [Crossref]

10. Murdoch D, Heel RC (1991) Amlodipine. A review of its pharmacodynamic and pharmacokinetic properties, and therapeutic use in cardiovascular disease. Drugs 41: 478-505. [Crossref]

11. Wellstein A, Palm D, Belz GG (1986) Affinity and selectivity of beta-adrenoceptor antagonists in vitro. J Cardiovasc Pharmacol 8 Suppl 11: S36-40. [Crossref]

12. Julius S (1988) Amlodipine in hypertension: an overview of the clinical dossier. $J$ Cardiovasc Pharmacol 12 Suppl 7: S27-33. [Crossref]

13. Sica DA (2002) Rationale for fixed-dose combinations in the treatment of hypertension: the cycle repeats. Drugs 62: 443-462. [Crossref]

14. Nayler WG. (1988) The potential for added benefits with B-blockers and calcium antagonists in treating cardiovascular disorders. Drugs 35 Suppl 4:1-8. [Crossref]

15. Waeber B, Feihl F, Ruilope LM (2009) Fixed-dose combinations as initial therapy for hypertension: a review of approved agents and a guide to patient selection. Drugs 69: 1761-1776. [Crossref]

16. Geddes JS (1983) Calcium antagonists and beta blockade--a useful combination. Postgrad Med J 59 Suppl 2: 62-69. [Crossref]

17. Mehta S, Shah M, Shah A et al. (2005) Efficacy and Tolerability of A Fixed Dose Combination of Amlodipin and Bisoprolol in Essential Hypertension. The Indian Practitioner 58,12: 751-759.

18. Rana R, Patil A. (2008) Efficacy, and Safety of Bisoprolol plus Amlodipine Fixed Dose Combination in Essential Hypertension. The Indian Practitioner Vol 61, 4: 225-234.

19. Shirure PA, Tadvi NA Bajait CS, et al. (2012) Comperative effect of fixed dose combination of Amlodipine + Bisoprolol versus Amlodipine and Bisoprolol alone on blood pressure in stage-2 essential hypertensive patients. Int J Med Res Health Sci 1 : 13-19.

20. Hostalek U, Czarnecka D2, Koch EM3 (2015) Treatment of Hypertensive Patients with a Fixed-Dose Combination of Bisoprolol and Amlodipine: Results of a Cohort study with More Than 10,000 Patients. Cardiol Ther 4: 179-190. [Crossref]

21. Hostalek U, Li L, Montenego P (2016) Bisoprolol/amlodipine combination therapy improves blood pressure control in patients with essential hypertension following monotherapy failure. CMRO; DOI:10.1080/03007995.2016.1205573

22. Dezii CM (2000) A retrospective study of persistence with single-pill combination therapy vs. concurrent two-pill therapy in patients with hypertension. Manag Care 9: 2-6. [Crossref]

23. Hostalek U, Czarnecka D, Kurzeja A, et al. Efficacy of and Adherence to a Fixed-dose Combination of Bisoprolol and Amlodipine in Hypertensive Patients with and without Type 2 Diabetes Mellitus or Coronary Artery Disease. J Heart Health 2015b; open access

24. Gradman AH, Basile JN, Carter BL, Bakris GL; American Society of Hypertension Writing Group (2010) Combination therapy in hypertension. J Am Soc Hypertens 4 : 42-50. [Crossref]

25. Düsing R (2010) Optimizing blood pressure control through the use of fixed combinations. Vasc Health Risk Manag 6: 321-325. [Crossref]

Copyright: (C2016 Hostalek U. This is an open-access article distributed under the terms of the Creative Commons Attribution License, which permits unrestricted use, distribution, and reproduction in any medium, provided the original author and source are credited. 